\title{
Comparison of the Thornthwaite method and pan data with the standard Penman-Monteith estimates of reference evapotranspiration in China
}

\author{
Deliang Chen ${ }^{1,2, *}$, Ge Gao ${ }^{1,2}$, Chong-Yu Xu ${ }^{3}$, Jun Guo ${ }^{4}$, Guoyu Ren ${ }^{2}$ \\ ${ }^{1}$ Regional Climate Group, Earth Sciences Centre, Gothenburg University, PO Box 460, 40530 Gothenburg, Sweden \\ ${ }^{2}$ Laboratory for Climate Studies/National Climate Center, China Meteorological Administration, \\ No. 46 Zhongguancun Nandajie, Haidian, Beijing 100081, China \\ ${ }^{3}$ Dept of Earth Sciences, Hydrology, Uppsala University, Villavägen 16, 75236 Uppsala, Sweden \\ ${ }^{4}$ Tianjin Meteorological Bureau, 100 Qixiangtai Road, Hexi District, Tianjin 300074, China
}

\begin{abstract}
Various methods are available to estimate reference evapotranspiration ( $\mathrm{ET}_{0}$ ) from standard meteorological observations. The Penman-Monteith method is considered to be the most physical and reliable method and is often used as a standard to verify other empirical methods. This study estimates and compares the monthly $\mathrm{ET}_{0}$ calculated by 3 methods at 580 Chinese stations over the last 50 yr. The Penman-Monteith method is used here as a reference, and its spatial and temporal differences with the Thornthwaite method and pan measurement are evaluated. The results show that: (1) in terms of spatial difference, the Thornthwaite estimates show different regional patterns, while pan measurements display a consistent regional pattern; (2) the temporal variability of $\mathrm{ET}_{0}$ is much better represented by pan measurements than by the Thornthwaite estimates. Overall, pan measurements are more useful than the Thornthwaite estimates if appropriate pan coefficients are determined. The Thornthwaite method only considers the temperature and latitude and gives unreliable results under dry conditions, e.g. in NW China. With reference to the Penman-Monteith estimates, the correction factors (pan coefficients) of pan measurements for the whole of China, and the regional averages over the 10 major drainage basins are determined. The average value lies between 0.6 and 0.8 , although a seasonal and regional difference is present.
\end{abstract}

KEY WORDS: Reference evapotranspiration · Water evaporation · Penman-Monteith · Thornthwaite · Pan · China Resale or republication not permitted without written consent of the publisher

\section{INTRODUCTION}

Evapotranspiration (ET) is an important component of the hydrological cycle and is essential for understanding land surface processes in climatology. In ecosystem and agriculture studies productivity is closely linked to actual ET. In practice, estimation of actual ET is often made by using information about potential ET and soil moisture (e.g. Dyck 1983). The potential ET, formally defined as 'wet-surface evaporation', is the ET governed by available energy and atmospheric conditions, as the water availability is not a limiting factor. Thus, potential ET is a function of atmospheric forcing and surface types. In order to remove the influence of surface types, the concept of reference evapotranspiration $\left(\mathrm{ET}_{0}\right)$ was introduced to study the evaporative demand of the atmosphere independent of crop type, crop development and management practices (Allen et al. 1998). $\mathrm{ET}_{0}$ is defined as the potential ET of grass. As water is abundantly available at the reference evapotranspiring surface, soil factors do not affect $\mathrm{ET}_{0}$. Relating $\mathrm{ET}_{0}$ to a specific surface (grass) rovides a reference from which ET for other surfaces can be estimated (Doorenbos \& Pruitt 1977, Allen et al. 1998).

There is a long history in the study of ET and relating it to meteorological variables, and the earliest method dates back to the beginning of the 19th century (e.g. 
Brutsaert 1982). Since then, many methods have been developed, which can be grouped into 6 categories (e.g. Xu \& Singh 2002): (1) water budget methods (e.g. Guitjens 1982); (2) mass-transfer methods (e.g. Harbeck 1962); (3) combination methods (e.g. Penman 1948, Monteith 1965), for the FAO Penman-Monteith method see Allen et al. (1998); (4) radiation-based methods (e.g. Priestley \& Taylor 1972); (5) temperature-based methods (e.g. Thornthwaite 1948, BlaneyCriddle 1950); and (6) pan evaporation methods (e.g. Allen et al. 1998). In general, techniques for estimating $\mathrm{ET}_{0}$ are based on one or more atmospheric variables, such as air temperature, solar or net radiation and humidity, or on some measurements related to these variables, like pan evaporation. Certain of these methods are accurate and reliable; others provide only a rough approximation. Most of the methods were developed for use in specific studies and are most appropriately applied to climates similar to that where they were developed (Chattopadhyay \& Hulme 1997).

The Penman-Monteith method is recommended as the sole standard by the FAO (Allen et al. 1998). The classic Penman-Monteith method combines both energy and mass balances to model $\mathrm{ET}_{0}$. It is based on fundamental physical principles, which guarantee the universal validity of the method. However, it needs a number of meteorological variables which may not be available everywhere. In this study, the PenmanMonteith method is used as a standard to evaluate the performance of other methods.

Since air temperature is a widely available variable, the Thornthwaite method, a simple method developed by Thornthwaite (1948) that uses only air temperature and latitude of the site to estimate $\mathrm{ET}_{0}$, is widely used in the literature. 'However, because it can be computed from temperature and latitude, it has been one of the most misused empirical equations generating inaccurate estimates of evapotranspiration for arid and semiarid irrigated areas' (Jensen 1973). Although the method is not recommended for use in areas that are not climatically similar to the east-central USA, where it was developed (Jensen 1973), it has also been used in China by some researchers (e.g. Ma \& Fu 2001). In this study, the applicability of the Thornthwaite method to climatic conditions in China is evaluated in view of the advantage that the method offers in calculating $\mathrm{ET}_{0}$ by using temperature alone, which is the most commonly determined meteorological variable in this part of the world.

The pan measurement method uses pan evaporation to estimate $\mathrm{ET}_{0}$ and is another common method, especially in Asian countries. The evaporation rate from pans filled with water is easily obtained. In the absence of rain, the amount of water evaporated $\left(\mathrm{mm} \mathrm{d}^{-1}\right)$ corresponds to the decrease in water depth. Pans provide a measurement of the integrated effect of radiation, wind, temperature and humidity on the evaporation from an open-water surface. Although the pan responds in a similar fashion to the same climatic factors affecting crop transpiration, several factors produce differences between loss of water from a water surface and that from the surface of crops (e.g. Allen et al. 1998). Storage of heat within the pan can be appreciable and may cause significant evaporation during the night, while most crops transpire only during the daytime. There are also differences in turbulence, temperature and humidity of the air immediately above the respective surfaces. Heat transfer through the sides of the pan affects the energy balance. However, the pan has proved its practical value and has been widely used to estimate $\mathrm{ET}_{0}$. Applying empirical coefficients to relate pan evaporation to $\mathrm{ET}_{0}$ for periods of 10 days or longer may be warranted (Allen et al. 1998). In China, the network for pan measurements is much denser than that of meteorological stations, but in order to make good use of pan evaporation data, spatial and seasonal variations of the pan coefficient need to be determined with accuracy. This study evaluates the performance of the pan measurement method and, by comparing it with Penman-Monteith ET, the seasonal and spatial variations of the pan coefficient are determined.

In China, many studies have attempted to estimate $\mathrm{ET}_{0}$ (Zhu \&Yang 1955, Lu et al. 1965, Qian \& Lin 1965, Gao et al. 1978), often for calculating the humidity index for climate regionalization. However, many of the investigations are regional in nature. Furthermore, only 1 of the methods is usually used in a region or at a small number of selected stations over the country (e.g. Axel 2000); comparison of different methods at regional and national scales is rare.

The objectives of this study are: (1) to estimate $\mathrm{ET}_{0}$ for the whole of China by using the Penman-Monteith and Thornthwaite methods and pan measurements; (2) to compare the Thornthwaite estimates and pan measurements with the Penman-Monteith estimates; and (3) to determine the extent to which the Thornthwaite method and the pan measurement data can be useful in estimating $\mathrm{ET}_{0}$ for various parts of China.

\section{DATA AND METHODS}

\subsection{Data on climate and water evaporation}

Monthly climate data from 1951 to 2000 at 580 meteorological stations (Fig. 1) in China were used in this study. They include the data needed to calculate $\mathrm{ET}_{0}$, namely mean air temperature, mean maximum and minimum temperature, mean sunshine duration, wind 
speed and humidity, as well as the monthly water evaporation in a pan of $20 \mathrm{~cm}$ diameter. The time series of most stations span more than $40 \mathrm{yr}$; those from only 10 and $1 \%$ of stations are between 35 and 40 yr for pan and monthly mean temperature, respectively.

\subsection{Penman-Monteith method}

According to the FAO (Allen et al. 1998), the PenmanMonteith method for $\mathrm{ET}_{0}\left(\mathrm{~mm} \mathrm{~d}^{-1}\right)$ can be expressed as:

$$
\mathrm{ET}_{0}=\frac{0.408 \Delta\left(R_{\mathrm{n}}-G\right)+\gamma \frac{900}{T+273} u_{2}\left(e_{\mathrm{s}}-e_{\mathrm{a}}\right)}{\Delta+\gamma\left(1+0.34 u_{2}\right)}
$$

where $R_{\mathrm{n}}$ is the net radiation at the crop surface $\left(\mathrm{MJ} \mathrm{m}^{-2} \mathrm{~d}^{-1}\right), G$ is the soil heat flux density $\left(\mathrm{MJ} \mathrm{m}^{-2}\right.$ $\left.\mathrm{d}^{-1}\right), T$ is the air temperature at $2 \mathrm{~m}$ height $\left({ }^{\circ} \mathrm{C}\right), u_{2}$ is the wind speed at $2 \mathrm{~m}$ height $\left(\mathrm{m} \mathrm{s}^{-1}\right), e_{\mathrm{s}}$ is the saturation vapor pressure $(\mathrm{kPa}), e_{\mathrm{a}}$ is the actual vapor pressure $(\mathrm{kPa}), e_{\mathrm{s}}-e_{\mathrm{a}}$ is the saturation vapor pressure deficit $(\mathrm{kPa}), \Delta$ is the slope vapor pressure curve $\left(\mathrm{kPa}{ }^{\circ} \mathrm{C}^{-1}\right)$ and $\gamma$ is the psychrometric constant $\left(\mathrm{kPa}^{\circ} \mathrm{C}^{-1}\right)$.

The computation of all data required for the calculation of $\mathrm{ET}_{0}$ followed Chapter 3 of FAO Paper 56 (Allen et al. 1998). The only difference is that in calculating solar radiation using Eq. (35) in Allen et al. (1998), the recommended values for the parameters $a_{s}$ and $b_{s}$ were not used; instead, we chose to use the regional values determined by Zhu (1982), as they were based on measurements in China. The constants were given for 4 regions: NE China, east China, NW China and the Tibetan Plateau.

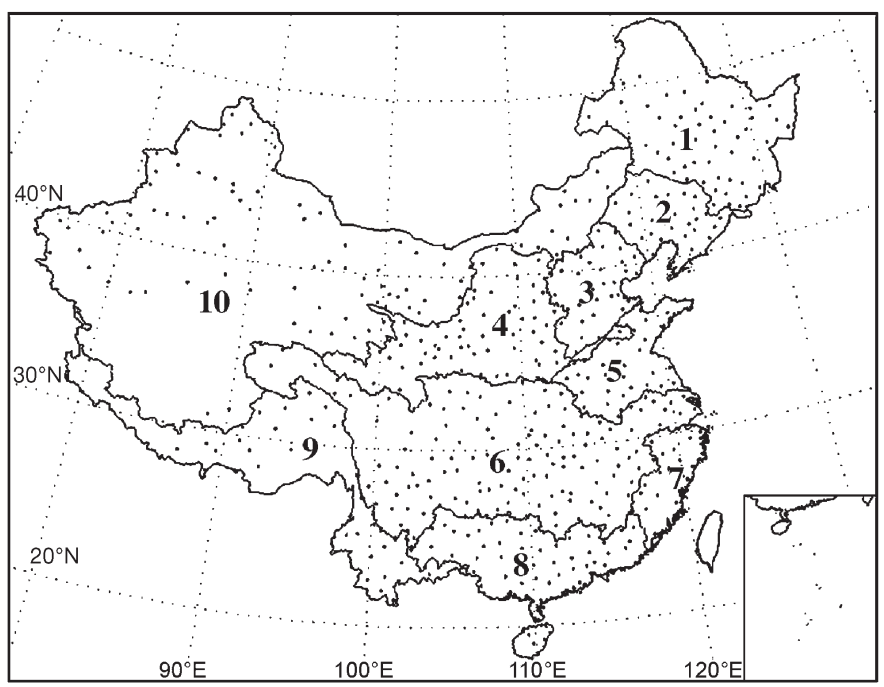

Fig. 1. Meteorological stations used in this study and the 10 drainage basins. Numbers denote the 10 drainage basins: 1: Song Hua River; 2: Liao River; 3: Hai River; 4: Yellow River; 5: Huai River; 6: Yangtze River; 7: SE rivers; 8: Pearl River; 9: SW rivers; 10: NW rivers

\subsection{Thornthwaite method}

Thornthwaite (1948) correlated mean monthly temperature with ET, as determined from water balance for valleys in the eastern USA where sufficient moisture water was available to maintain active transpiration. The Thornthwaite formula for monthly $\mathrm{ET}_{0}(\mathrm{~mm})$ is:

$$
\mathrm{ET}_{0}=16 d(10 T / I)^{a}
$$

Where $T$ is the mean temperature for the month (in $\left.{ }^{\circ} \mathrm{C}\right), I$ is the annual thermal index, i.e. the sum of monthly indices $\mathrm{i}\left[\mathrm{i}=(T / 5)^{1.514}\right], d$ is a correction factor which depends on latitude and month, and $a$ is $0.49+0.0179 I-0.0000771 I^{2}+0.000000675 I^{3}$.

\subsection{Pan evaporation}

There are different pans for measuring evaporation, and the one with a diameter of $20 \mathrm{~cm}$ and a height of $10 \mathrm{~cm}$ is used in China. It is made of metal and has a veil on it. It is installed $70 \mathrm{~cm}$ above the ground. The water level is measured at 20:00 h Beijing time every day. A base level of $20 \mathrm{~mm}$ water depth is set daily. The evaporation is equal to base + rainfall - remains. Since the 1980s, another type of pan (E-601), $61.8 \mathrm{~cm}$ in diameter, has been used in China. Parallel measurements at selected stations in China show that the small pan and the E-601 pan give different results; however, the difference is fairly systematic so that a correction factor has been established (Liu et al. 1998). From 1995, the E-601 pan was replaced by another pan (E-601B) made of glass fiber reinforced plastics, and until June 1998 the entire network of about 600 stations in China had been equipped with this type of pan. The values observed using this pan are closer to actual evaporation from small and middle-sized bodies of water than those of the other pans. A coefficient for conversion from the small evaporation pan to the E-601B pan in China was obtained by Ren et al. (2002).

\subsection{Evaluation}

Due to its solid physical basis, the $\mathrm{ET}_{0}$ estimated by the Penman-Monteith method is considered the most reliable and used as the reference to which the other 2 estimates are compared. The comparison is made for each station on seasonal and annual bases. For the spatial distribution the following 3 measures are given: (1) relative bias, (2) relative root mean square error (RMSE), and (3) correlation coefficient. Note that the relative biases and errors are normalized against the means of the Penman-Monteith estimates. 


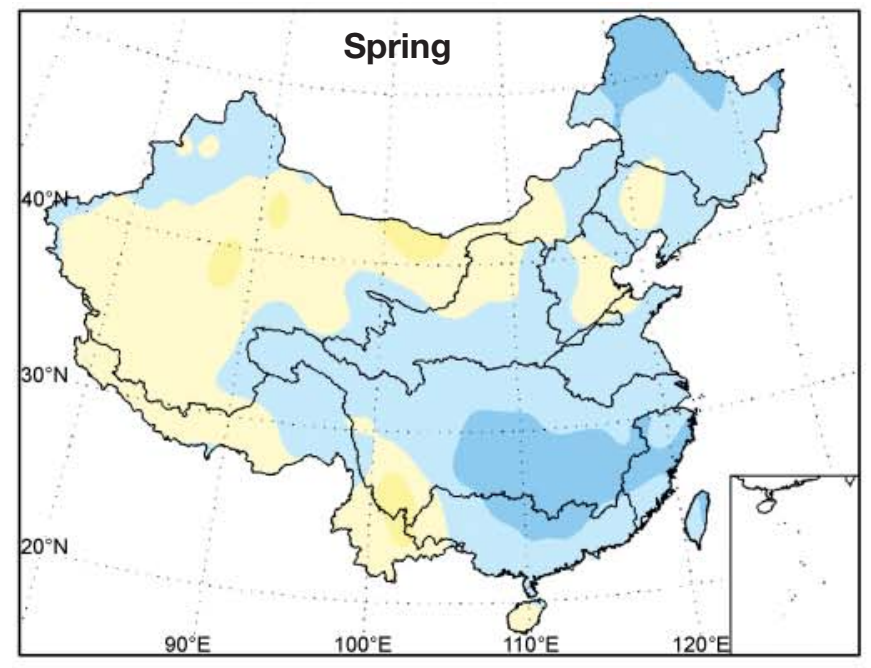

\begin{tabular}{c|ccccc}
\hline & 1 & 1 & 1 & 1 \\
124.5 & 200 & 300 & 400 & 500563.5
\end{tabular}
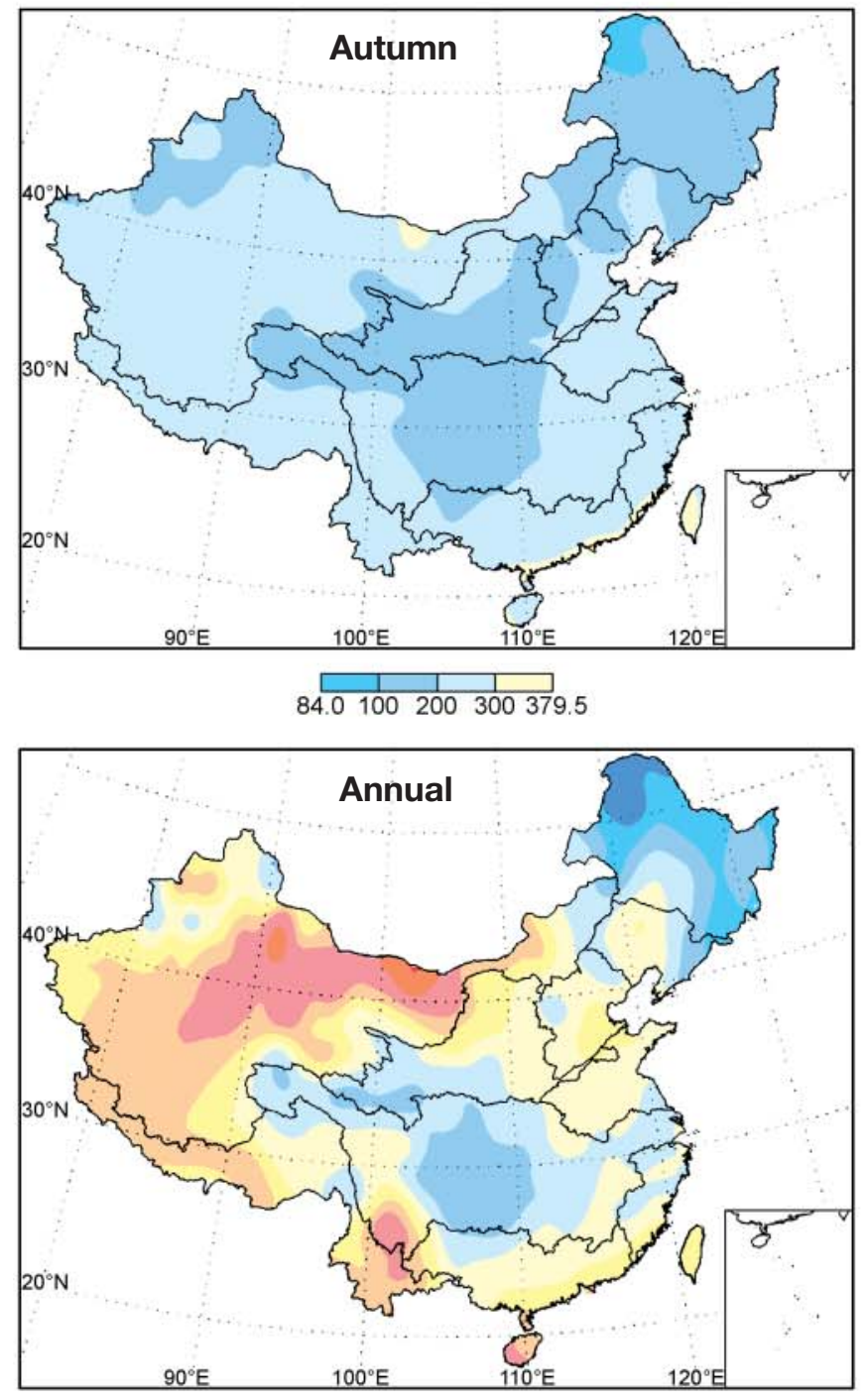

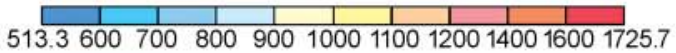

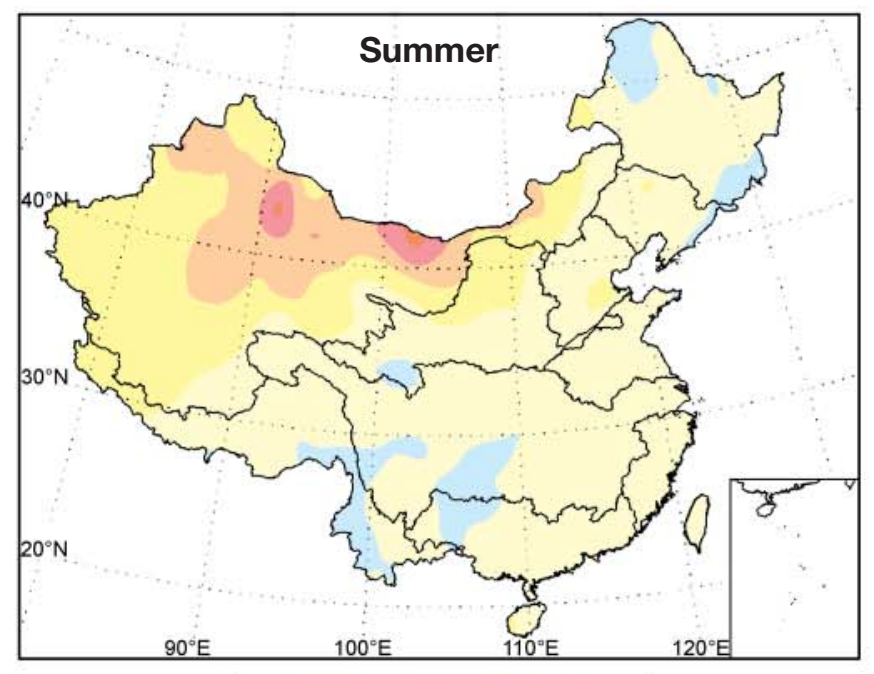

\begin{tabular}{ccccccccc}
\hline & 1 & 1 & 1 & 1 & 1 & 1 \\
208.6300 & 400 & 500 & 600 & 700 & 800848.0
\end{tabular}

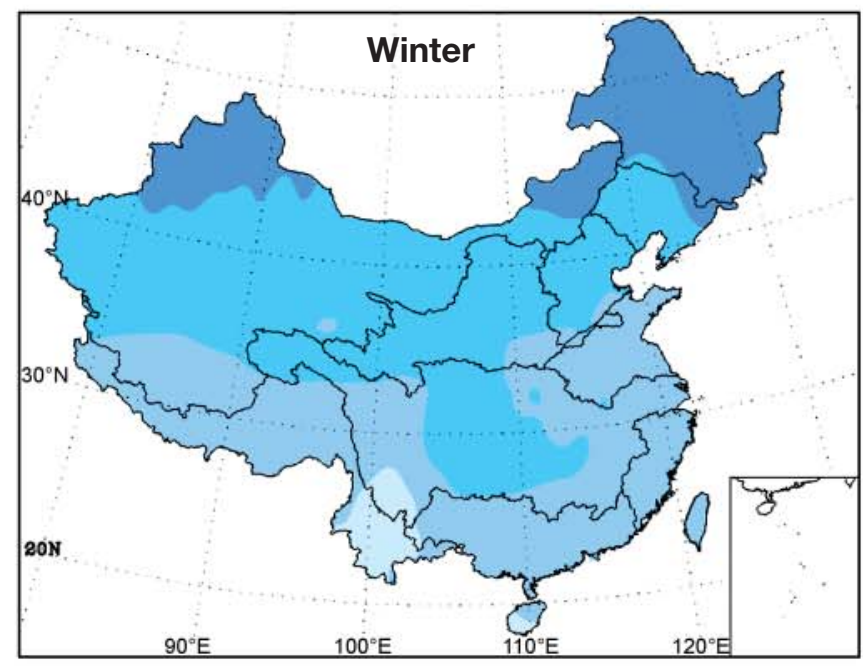

6.9 \begin{tabular}{cccccc}
\hline & $\frac{1}{1}$ & 1 & 1 & 1 & 1 \\
60 & 100 & 200 & 300 & 304.4
\end{tabular}
Fig. 2. Seasonal and annual mean reference evapotranspiration $\left(\mathrm{ET}_{0}, \mathrm{~mm}\right)$ estimated by the Penman-Monteith method 
The biases and RMSE summarize the error statistics over the whole period and give an averaged difference in 2 different ways. In reality, variation from year to year is large, and how this variation is reflected in the estimate gives a good indication about how the method works. Furthermore, the temporal variation of evaporation is considered as an important indicator of climate change (Peterson et al. 1995, Brutsaert \& Parlange 1998).

\section{RESULTS AND DISCUSSION}

\subsection{Penman-Monteith method}

Fig. 2 shows the seasonal and annual $\mathrm{ET}_{0}$ over China, estimated from the Penman-Monteith method. In spring, there is a great gradient of air humidity over China. The distribution pattern of the humidity resembles that of $\mathrm{ET}_{0}$, indicating the important role played by air humidity during this season. In summer the spatial differences are relatively small, while the absolute values are relatively high due to the strong solar radiation in the south and the low humidity values in the north. The maximum value occurs in the NW part of the country where the summer monsoon has a negligible influence. Autumn reveals a fairly homogeneous spatial distribution, while winter shows a clear southnorth gradient, indicating the dominant role of radiation. The annual distribution shows low ET in the middle of the Yangtze River Basin and in NE China and high ET in NW and SW China.

\subsection{Thornthwaite method}

An examination of the seasonal and annual estimates of the Thornthwaite in comparison with the Penman-Monteith estimates shows great differences, especially on a regional basis. Fig. 3 shows the annual biases with the Penman-Monteith method. Although not shown, on a seasonal basis the Thornthwaite method overestimates the $\mathrm{ET}_{0}$ in SE China and underestimates it in other parts of China in spring, summer and autumn, whereas there is an underestimation in winter over the entire country. Since the Thornthwaite method is an empirical method based on observations made in the eastern USA, its application under Chinese climatic conditions may be problematic, at least with its original parameter values. The annual bias indicates that the Thornthwaite method overestimates $\mathrm{ET}_{0}$ over the monsoon affected areas where climate is relatively humid, while for arid and semiarid parts of China it produces an underestimation.

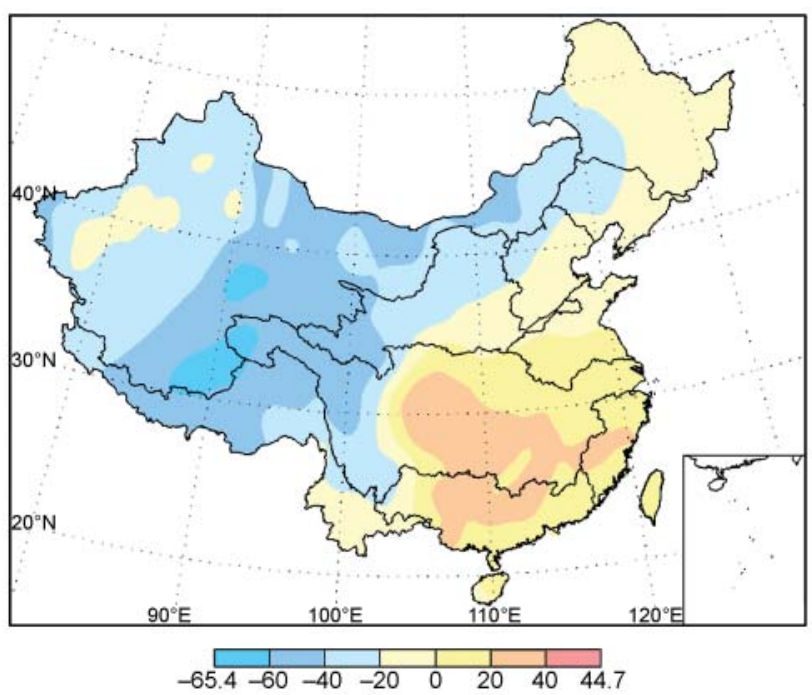

Fig. 3. Annual relative bias (\%) of reference evapotranspiration estimated by the Thornthwaite method compared with the Penman-Monteith method

Fig. 4 shows the distribution of annual relative RMSE of the Thornthwaite estimates. The annual relative RMSE ranges from 3.8 to $65.7 \%$ across China.

The correlation coefficients between the 2 estimates on an annual basis are shown in Fig. 5. On a seasonal basis (not shown) there exists a better agreement during spring and summer than during winter and autumn. The regional differences are fairly large over all 4 seasons. On average, there is a moderate correlation between the two, indicating that the Thornthwaite method only accounts for a small part of the temporal variability over China. Furthermore, on an annual basis, the NW and part of inner Mongolia show a neg-

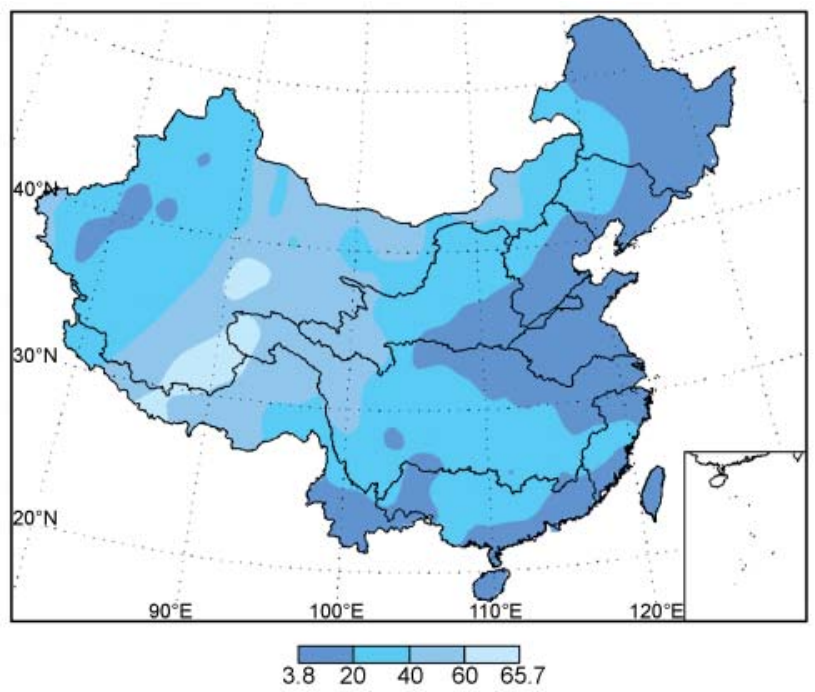

Fig. 4. Annual relative RMSE (\%) of reference evapotranspiration estimated by the Thornthwaite method compared with the Penman-Monteith method 


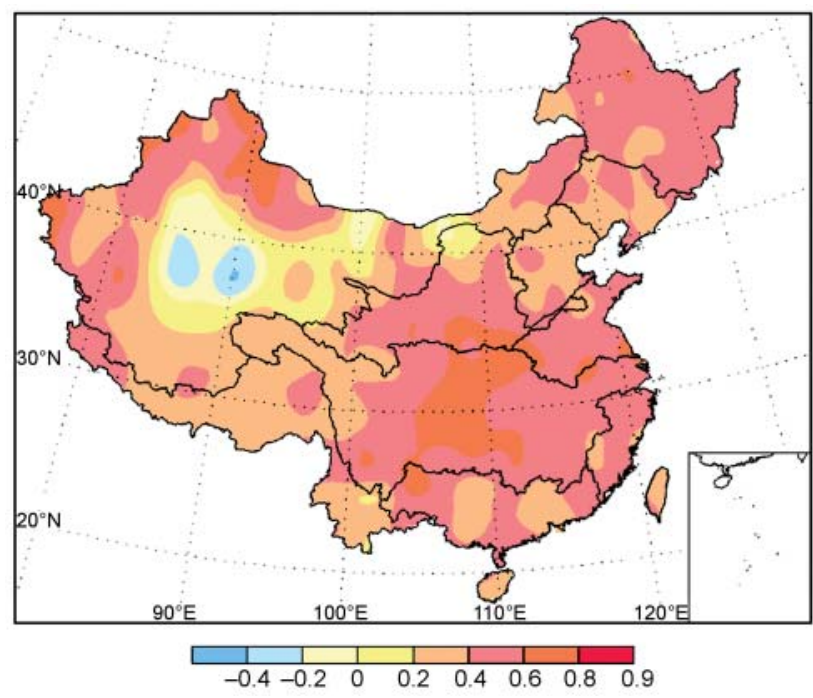

Fig. 5. Annual correlations of reference evapotranspiration estimates from the Thornthwaite method with those of the Penman-Monteith method

ative correlation. This implies that the Thornthwaite method does not follow the change in the PenmanMonteith estimates with time, which disqualifies use of the former in climate change studies in China.

\subsection{Pan measurement}

Since pan measurements are made for the water surface of a relatively small area, a large positive bias is expected. Fig. 6 shows a consistent regional picture of the bias with high values in northern and NW areas

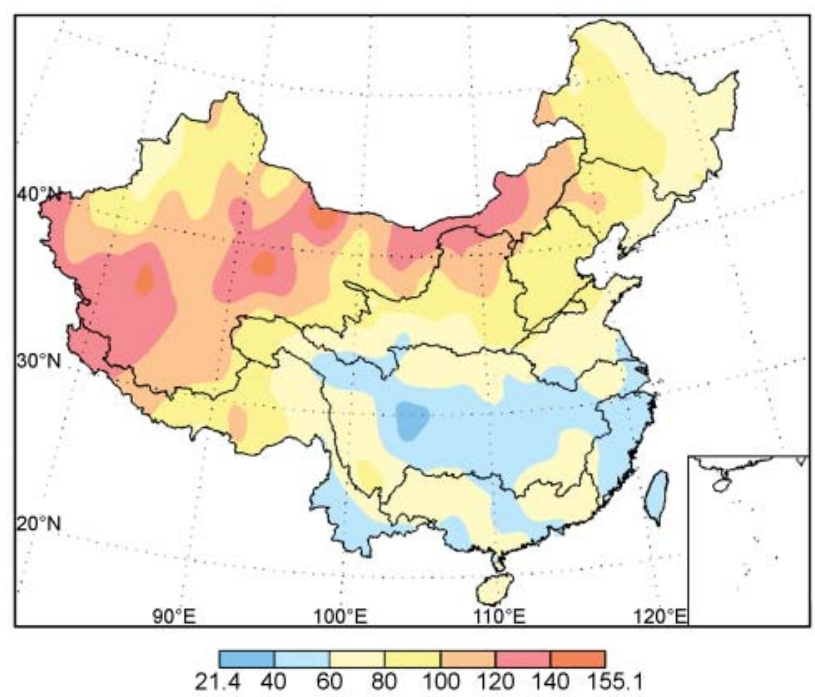

Fig. 6. Annual relative bias (\%) of reference evapotranspiration estimated by pan measurement compared with the Penman-Monteith method and low values in the south. This is certainly a reflection of the different humidity conditions across China. The annual estimates have a relative bias from $21.4 \%$ in the south to $155.1 \%$ in the north and NW.

Due to the consistent positive bias over all seasons and regions, a large relative RMSE is expected. Fig. 7 displays the annual relative RMSE for pan measurement, which to a large extent is caused by the positive bias showed in Fig. 6. Pan measurements in part of the south are fairly close to the Penman-Monteith estimates on an annual basis.

Because the bias is consistently positive over the entire country, the deviation of pan measurement from the Penman-Monteith estimate is fairly systematic over various regions. Seasonal (not shown) and annual correlation coefficients (Fig. 8) are all positive, which shows that temporal variation in pan measurement follows that of the Penman-Monteith estimates. For most regions and seasons the correlations are fairly high, indicating that the pan measurement simulates the change in all relevant meteorological conditions fairly well. This may not be surprising as pan evaporation measures the integrated effect of radiation, wind, temperature and humidity on the evaporation from an open-water surface.

The high correlation and systematic difference make pan measurement a suitable substitute for the Penman-Monteith estimates. In fact, this kind of measurement has been widely used (e.g. Guo et al. 2002). Typically, pan measurements are directly used, together with precipitation, as the inputs to a hydrological model, and then the model is calibrated against other observations to get suitable model parameters. It should be noted that the values of the related para-

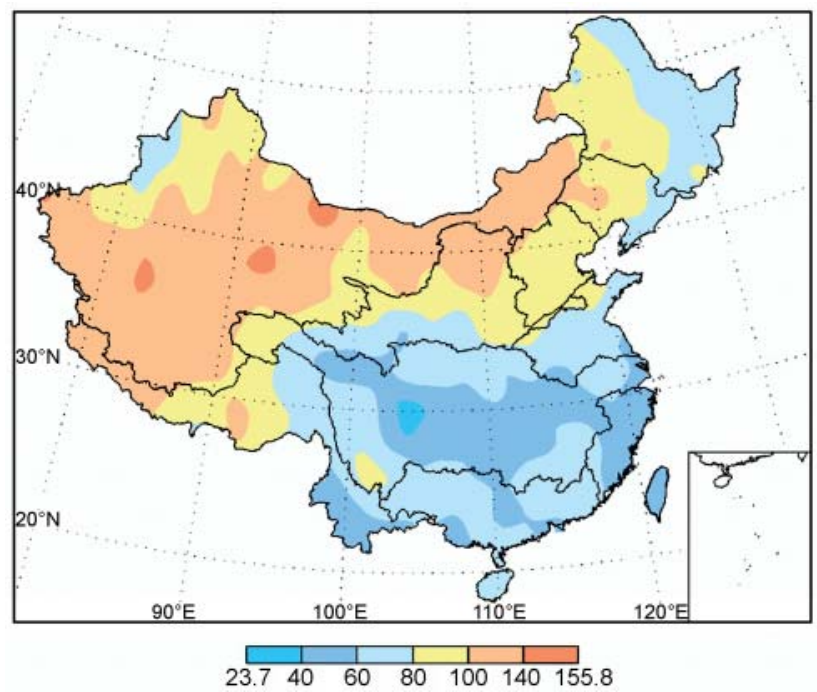

Fig. 7. Annual relative RMSE (\%) of reference evapotranspiration estimated by pan measurement compared with the Penman-Monteith method 


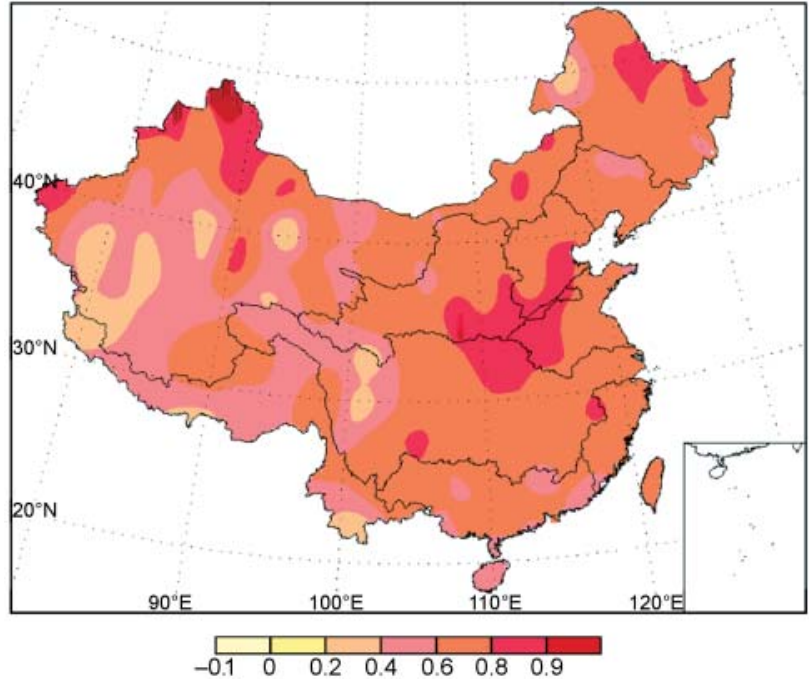

Fig. 8. Annual correlations of reference evapotranspiration estimates from pan measurement with those of the PenmanMonteith method

meters calibrated in this way will be biased from the true values. Ideally, the input to the model should be the pan measurement data multiplied by the pan coefficient as obtained in this study so that the parameters determined will be reasonable and the model simulation realistic. In addition, some other applications, such as water requirement estimates for a crop, require the $\mathrm{ET}_{0}$ as defined by the FAO. Therefore, a correction of the pan measurement by multiplying it by the pan coefficient would also be necessary to give a better estimate of $\mathrm{ET}_{0}$.

The correction factor (pan coefficient), defined as the ratio of the Penman-Monteith estimate to that of the pan measurement, is calculated for each station and month and interpolated to give a regional distribution pattern for the whole of China. Fig. 9 shows the ratios on seasonal and annual bases. There is some variation in the ratio across China. As a whole, the ratio varies between 0.4 and 0.8 with an average of about 0.6 . This spatially interpolated seasonal correction factor can be used to convert pan evaporation measurements into $\mathrm{ET}_{0}$ in places where there are no meteorological data available to calculate $\mathrm{ET}_{0}$.

\subsection{Summary}

For hydrological applications, the drainage basin is the unit to consider and the characteristic of the time series is of importance. The long-term variation properties of pan measurements and $\mathrm{ET}_{0}$ estimated by the Penman-Monteith and Thornthwaite methods, as measured by the temporal trend and the correlation coefficient of the linear trend, are summarized in Table 1 for the 10 major catchments in China. In Table 1 the trend is the slope of the linear regression, with evaporation as the dependent variable and time as the independent variable. Table 1 shows that: (1) According to the Penman-Monteith estimates, evapotranspiration in 3 catchments has an increasing trend, of which 1 is significant (Song Hua in NE China); the remaining catchments have a decreasing trend, of which 4 are significant. (2) In 9 out of 10 catchments the pan estimates show the same trend direction as those of the Penman-Monteith method but are greater in magnitude in most cases. The only exception is the Yellow River Basin, where a decreasing trend is found with pan measurements. (3) The Thornthwaite estimate gives an increasing trend for all the catchments which is very different from the other 2 methods. The reason is that in most regions of China air temperature has been increasing during recent decades, while wind speed and solar radiation have been significantly decreasing during the same period (e.g. Xu et al. 2004). Accordingly, ET calculated by the Thornthwaite method, which uses only temperature as input data, shows an increasing trend for all catchments, while the Penman-Monteith method and pan evaporation provide a measurement of the integrated effect of radiation, wind, temperature and humidity.

Table 2 gives the relative biases and RMSE and the correlation coefficient between the Thornthwaite method, and pan and Penman-Monteith estimates: (1) For the long-term average values there is a systematic deviation between pan evaporation and PenmanMonteith evapotranspiration, which resulted in a consistent bias between the 2 estimates. The correlation coefficient between the 2 estimates is quite high and significant. Thus, pan measurement can be used to

Table 1. Long-term trend of reference evapotranspiration $\left(\mathrm{ET}_{0}, \mathrm{~mm}_{\mathrm{yr}}{ }^{-1}\right)$ estimated by the Penman-Monteith and Thornthwaite methods and pan evaporation. R: correlation coefficient of the linear trend; ${ }^{*}$ statistically significant at $5 \%$ level

\begin{tabular}{|c|c|c|c|c|c|c|}
\hline & \multicolumn{2}{|c|}{ Penman-Monteith } & \multicolumn{2}{|c|}{ Thornthwaite } & \multicolumn{2}{|c|}{ Pan } \\
\hline & Trend & $\mathrm{R}$ & Trend & $\mathrm{R}$ & Trend & $\mathrm{R}$ \\
\hline 1 Song Hua River & 0.99 & $0.38^{*}$ & 1.15 & $0.68^{*}$ & 1.49 & 0.25 \\
\hline 2 Liao River & 0.32 & 0.11 & 0.97 & $0.53^{*}$ & 0.16 & 0.02 \\
\hline 3 Hai River & -0.67 & -0.21 & 1.11 & $0.55^{*}$ & -3.33 & $-0.36^{*}$ \\
\hline 4 Yellow River & 0.05 & 0.02 & 0.63 & $0.49^{*}$ & -3.04 & $-0.40^{*}$ \\
\hline 5 Huai River & -0.52 & -0.15 & 0.69 & $0.35^{*}$ & -4.51 & $-0.47^{*}$ \\
\hline 6 Yangtze River & -1.11 & $-0.47^{*}$ & 0.17 & 0.15 & -1.76 & $-0.32^{*}$ \\
\hline 7 Southeast rivers & -1.11 & $-0.34^{*}$ & 0.44 & $0.32^{*}$ & -1.39 & -0.24 \\
\hline 8 Pearl River & -1.25 & $-0.47^{*}$ & 0.33 & $0.38^{*}$ & -2.12 & $-0.35^{*}$ \\
\hline 9 Southwest rivers & -0.14 & -0.08 & 0.45 & $0.54^{*}$ & -0.84 & -0.17 \\
\hline 10 Northwest rivers & -1.57 & $-0.63^{*}$ & 0.67 & $0.54^{*}$ & -3.11 & $-0.42^{*}$ \\
\hline
\end{tabular}




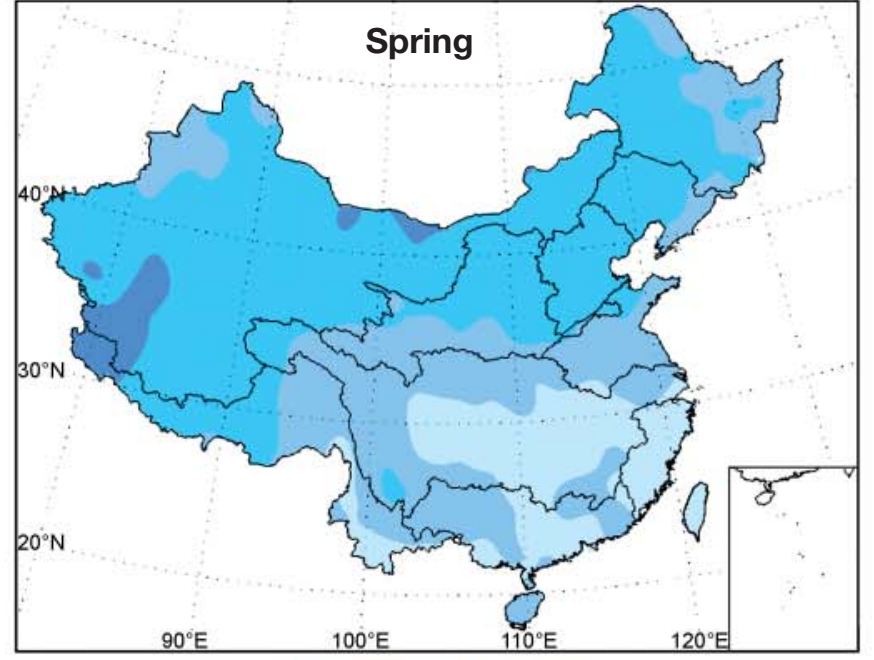

\begin{tabular}{ccccc}
\hline & $\frac{1}{1}$ & $\frac{1}{1}$ & \\
0.4 & 0.5 & 0.6 & 0.7 & 0.8
\end{tabular}

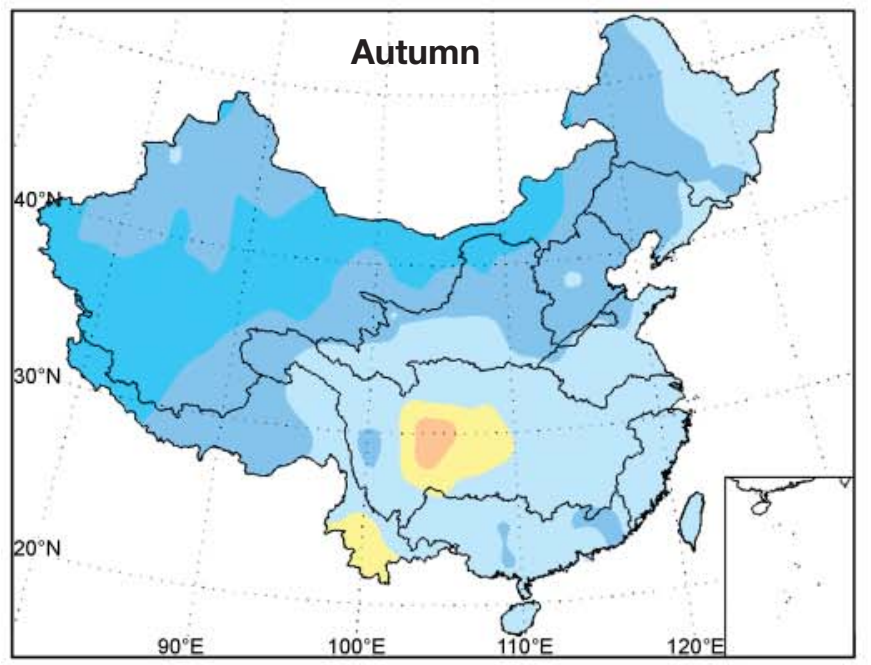

\begin{tabular}{cccccc}
\hline & $\frac{1}{4}$ & $\frac{1}{1}$ & $\frac{1}{1}$ & 1 \\
0.4 & 0.5 & 0.6 & 0.7 & 0.8 & 0.9
\end{tabular}

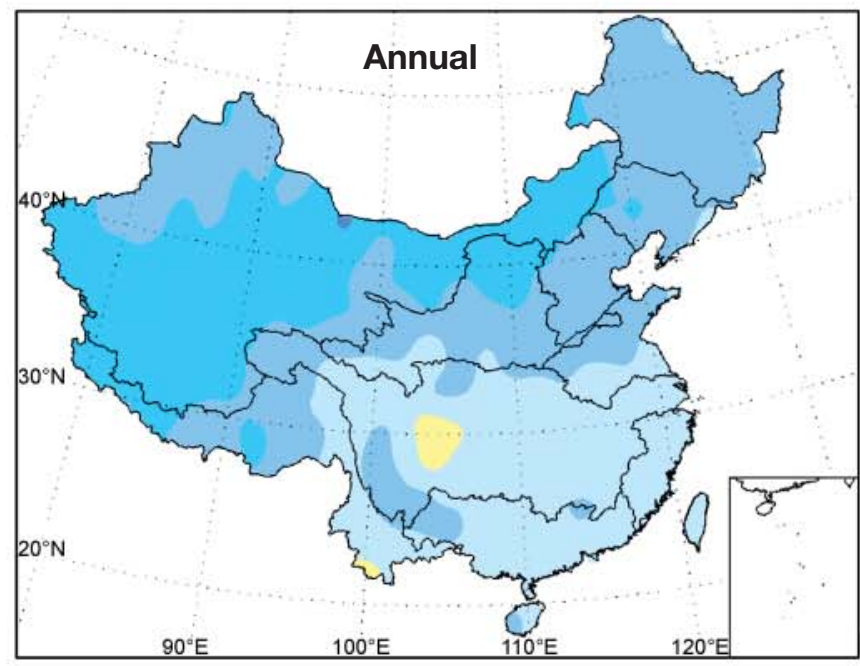

\begin{tabular}{ccccc}
\hline & $\frac{1}{1}$ & $\frac{1}{1}$ & $\frac{1}{}$ \\
\hline 0.4 & 0.5 & 0.6 & 0.7 & 0.8
\end{tabular}

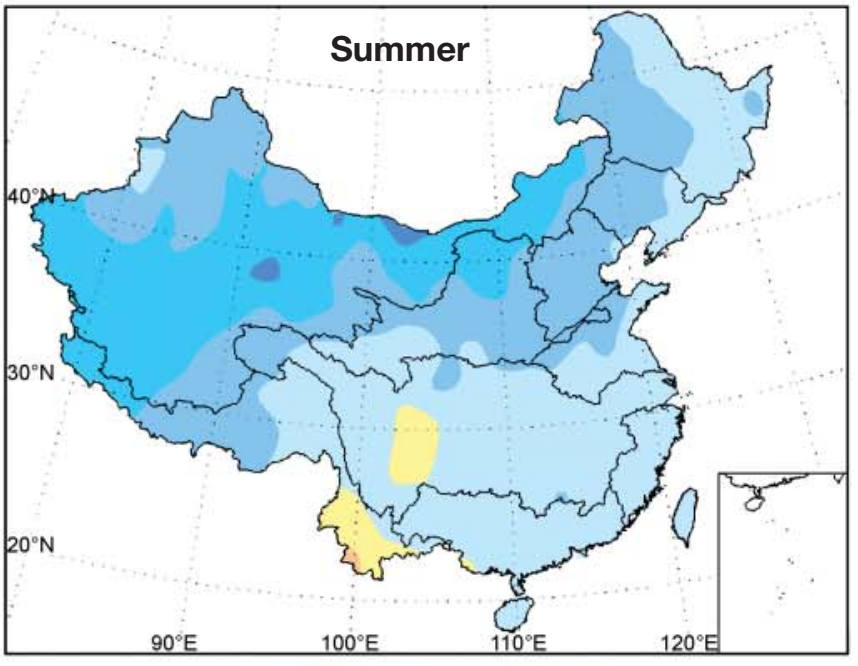

\begin{tabular}{ccccccc}
\hline & & $\frac{1}{1}$ & $\frac{1}{\square}$ \\
0.4 & 0.5 & 0.6 & 0.7 & 0.8 & 0.9
\end{tabular}

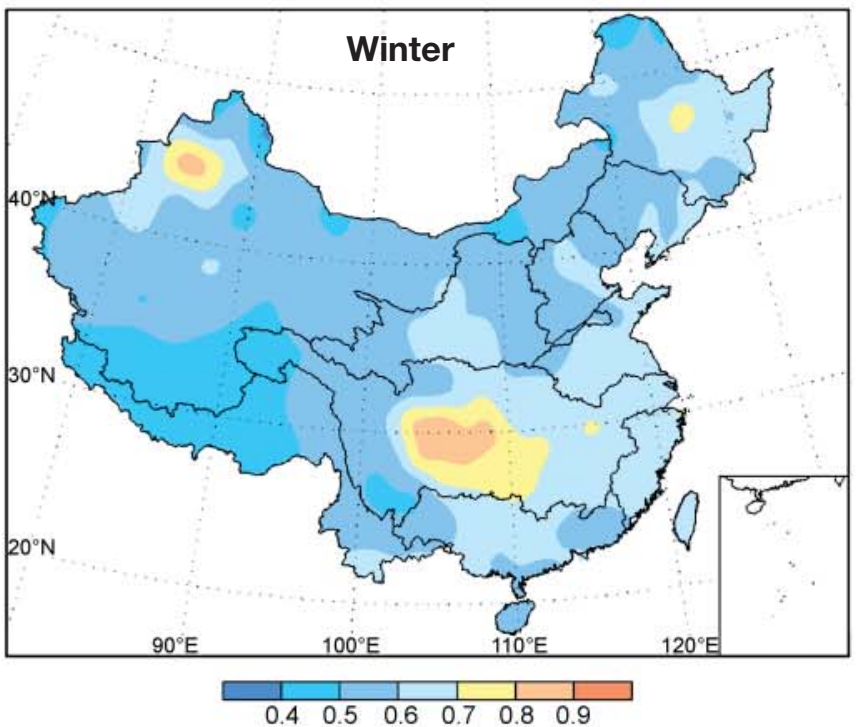

Fig. 9. Seasonal and annual ratio of reference evapotranspiration $\left(\mathrm{ET}_{0}\right)$ estimation by the Penman-Monteith method to that of pan measurement (pan coefficient) 
Table 2. Seasonal and annual statistics of reference evapotranspiration $\left(\mathrm{ET}_{0}\right)$ estimates from the Thornthwaite and pan methods in comparison to the Penman-Monteith method. The relative bias and RMSE are calculated in relation to the Penman-Monteith estimate $(\%)$. Correlation coefficient $(\mathrm{R})$ is the correlation between the seasonal/annual values of the Thornthwaite method, and pan and Penman-Monteith methods. Bias $(\%)=$ Bias $/ E_{\text {Penman-Monteithi }}$ RMSE $(\%)=$ RMSE $/ E_{\text {Penman-Monteithi }}$ Ratio $=$ pan coefficient $=$ $\mathrm{ET}_{\text {Penman-Monteith }} / \mathrm{ET}_{\text {pan or Thornthwaitei }}{ }^{\mathrm{x}}$ not statistically significant at $5 \%$ level

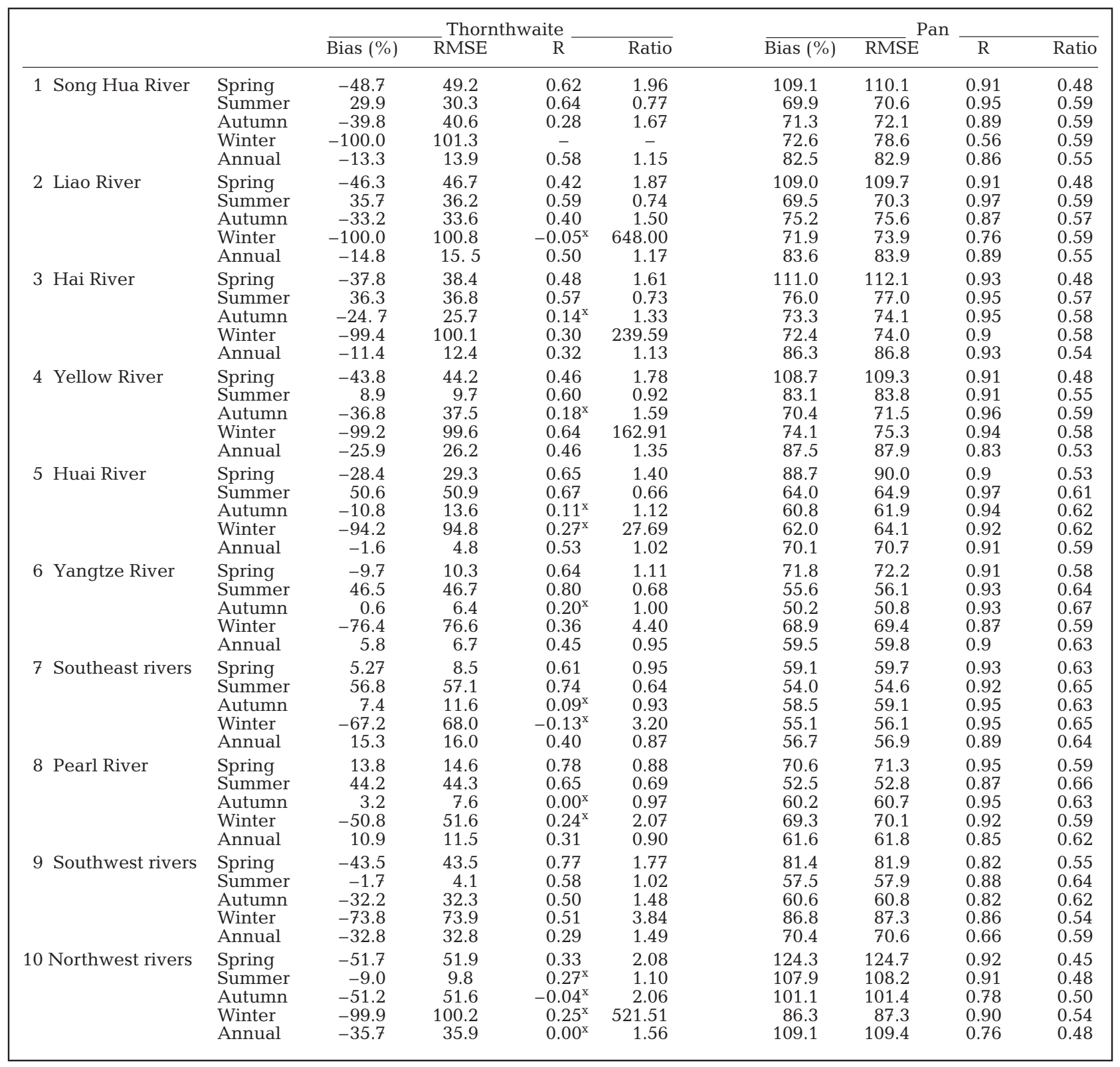

represent the Penman-Monteith evapotranspiration provided that a correction is made by multiplying it by the pan coefficient. (2) The difference between the Thornthwaite and Penman-Monteith estimates as measured by the bias and RMSE shows no consistent relationship, and the correlation coefficient between the 2 estimates is much lower than for pan evaporation. This means that a large unpredictable error is expected if the Thornthwaite method is used to estimate $\mathrm{ET}_{0}$ in China.

\section{CONCLUSIONS}

(1) $\mathrm{ET}_{0}$ estimated by the Penman-Monteith method as recommended by the FAO shows large regional differences and seasonal variation over China.

(2) The Thornthwaite method overestimates $\mathrm{ET}_{0}$ in SE China where $\mathrm{ET}_{0}$ is low, and underestimates it in northern and NW parts where $\mathrm{ET}_{0}$ is high. In addition, this method does not follow the temporal variation well. The reason is that the Thornthwaite method uses 
only temperature as input data while, depending on the season and region, other variables like wind speed, humidity and solar radiation may determine the magnitude of ET. Because the Thornthwaite method cannot capture the spatial and temporal patterns of $\mathrm{ET}_{0}$, its usefulness in China is questionable.

(3) Pan measurement shows a systematic deviation from the Penman-Monteith estimate, and the seasonal and regional structures of this deviation are fairly stable. Furthermore, the temporal variation of $\mathrm{ET}_{0}$ is much better represented by pan measurement than by the Thornthwaite method. The positive and high correlation in time plus the consistent regional and seasonal deviation indicate that pan measurement can be a good substitute for the Penman-Monteith method if appropriate corrections are made to account for the systematic errors.

(4) The correction factors (pan coefficients) for 10 major river basins in China can be used to estimate regional $\mathrm{ET}_{0}$ from pan measurement. The annual mean pan coefficient ranges from 0.4 to 0.8 with an average of about 0.6 for the whole of China.

(5) In most drainage basins of China, the values of $\mathrm{ET}_{0}$ estimated by Penman-Monteith and water evaporation measured by pan have decreased in the past 50 yr. A recent study (Xu et al. 2004) shows that the decrease in ET is the result of decrease in wind speed and net radiation, which in turn can be attributed, to some extent, to the increase in urban areas and air pollution. Further study is needed to evaluate how the decrease in $\mathrm{ET}_{0}$ affects the actual ET.

Acknowledgements. This research was supported by grants from the Chinese Ministry of Science and Technology (2001BA611B-01), the Swedish Research Council (VR), the Swedish Foundation for International Cooperation in Research and High Education, Chinese Ministry of Water Resources, Chinese Academy of Sciences and the China Meteorological Administration.

\section{LITERATURE CITED}

Allen RG, Pereira LS, Raes D, Smith M (1998) Crop evapotranspiration-guidelines for computing crop water requirements. FAO Irrigation \& Drainage Paper 56. FAO, Rome

Axel TH (2000) Spatial and temporal characteristics of potential evapotranspiration trends over China. Int J Climatol 20:381-396

Blaney HF, Criddle WD (1950) Determining water requirements in irrigated areas from climatological irrigation data. Soil Conservation Service Tech Paper No. 96, US Department of Agriculture, Washington, DC

Brutsaert W (1982) Evaporation into the atmosphere. Reidal, Dordrecht

Brutsaert W, Parlange MB (1998) Hydrological cycle explains the evaporation paradox. Nature 396:30

Chattopadhyay N, Hulme M (1997) Evaporation and potential

Editorial responsibility: Helmut Mayer,

Freiburg, Germany evapotranspiration in India under conditions of recent and future climatic change. Agric For Meteorol 87:55-74

Doorenbos J, Pruitt OW (1977) Crop water requirements. FAO Irrigation \& Drainage Paper 24. Land and Water Development Division, FAO, Rome

Dyck S (1983) Overview on the present status of the concepts of water balance models. In: Van der Beken A, Herrmann A (eds) Proc Hamburg Workshop on New Approaches in Water Balance Computations. IAHS Publ 148:3-19

Gao GD, Lu YR, Li HJ (1978) The calculation and distribution of maximum potential evaporation in China. Acta Geogr Sinica 33:102-111 (in Chinese with English abstract)

Guitjens JC (1982) Models of alfalfa yield and evapotranspiration. Proc Am Soc Civil Engineers. J Irr Drain Div-ASCE 108(IR3):212-22

Guo SL, Wang JX, Xiong LH, Ying AW, Li DF (2002) A macroscale and semi-distributed monthly water balance model to predict climate change impacts in China. J Hydrol 268:1-15

Harbeck GE (1962) A practical field technique for measuring reservoir evaporation utilizing mass-transfer theory. Geological Survey Professional Paper 272-E. Government Printing Office, Washington, DC, p 101-105

Jensen ME (ed) (1973) Consumptive use of water and irrigation water requirements. American Society of Civil Engineers, New York

Liu XN, Wang SQ, Wu ZX, Wang Y (1998) Comparative analysis on two kinds of observed evaporation data in China. Q J Appl Meteorol 9:321-328 (in Chinese with English abstract)

Lu QY, Wei L, Du ZP, Lin ZY (1965) A study of wet and dry periods in China and a delineation of wet and dry regions. Acta Geogr Sinica 31:15-24 (in Chinese with English abstract)

Ma ZG, Fu CB (2001) Trend of surface humid index in the arid area of Northern China. Acta Meteorol Sinica 59:737-746 (in Chinese with English abstract)

Monteith JL (1965) Evaporation and environment. Proc Symp Soc Exp Biol 19:205-234

Penman HL (1948) Natural evaporation from open water, bare soil and grass. Proc R Soc Lond 193:120-145

Peterson TC, Golubev VS, Groisman PY (1995) Evaporation losing its strength. Nature 377:687-688

Priestley CHB, Taylor RJ (1972) On the assessment of the surface heat flux and evaporation using large-scale parameters. Mon Weather Rev 100:81-92

Qian JL, Lin ZG (1965) A preliminary study of dry and wet climatic regionalization in China. Acta Geogr Sinica 31: 1-14 (in Chinese with English abstract)

Ren ZH, Li MQ, Zhang WM (2002) Conversion coefficient of the small evaporation pan into the E-601B pan in China. Q J Appl Meteorol 13:508-512 (in Chinese with English abstract)

Thornthwaite CW (1948) An approach toward a rational classification of climate. Geogr Rev 38:55-94

Xu CY, Singh VP (2002) Cross-comparison of mass-transfer, radiation and temperature based evaporation models. Water Res Manag 16:197-219

Zhu CH (1982) A further discussion on the climatological calculating method of total radiation (II). J Nanjing Inst Meteorol 2:196-206 (in Chinese with English abstract)

Zhu GK, Yang JZ (1955) The application of meteorological records in economic construction, Part II: a preliminary study of evaporation in various parts of China. J Meteorol 26:1-24 (in Chinese with English abstract)

Submitted: August 30, 2004; Accepted: November 30, 2004

Proofs received from author(s): January 3, 2005 